\title{
Synthesis and Characterization of New Comb-shape Copolymers Based on 3,5-Isoxazolines.
}

\author{
Joel A. Passo (PG)* and A. A. Merlo (PQ)
}

Instituto de Química, Universidade Federal do Estado do Rio Grande do Sul, Av. Bento Gonçalves, 9500, Porto Alegre, RS, Brasil - CEP 91.501-970.

\section{*passoja@gmail.com}

Keywords: Isoxazolines; polyacrylates; Copolymers.

\section{INTRODUCTION}

Copolymerization is one of the important techniques adopted in effecting systematic changes in the properties of commercially important polymers ${ }^{1}$. It is possible to tune the polymer taking advantages from the monomers for especial application improving the characteristics of polymer turning it more interesting commercial and for technology applications ${ }^{2}$.

\section{RESULTS AND DISCUSSION}

In this work we prepared new comb-shape polyacrylates copolymers 3a-e through radical polymerization as outlined in Scheme 1. The copolymers are comprised of monomer $\mathbf{1 a - d}$ and $\mathbf{2}$.

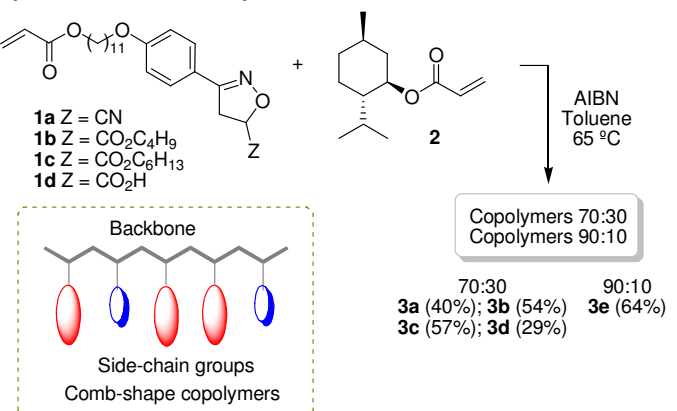

Scheme 1. Synthesis of comb-shape copolymers 3a-e.

The preparation of the monomers ${ }^{3} \mathbf{1 a - d}$ (Scheme 2) began with the alkylation of aldehyde 4 with 11-bromo-1-undecanol ( $\left.\mathrm{MeCN} / \mathrm{K}_{2} \mathrm{CO}_{3}\right)$ to gave 5 , followed by oximation reaction to yield the corresponding oxime 6 in a good yields.

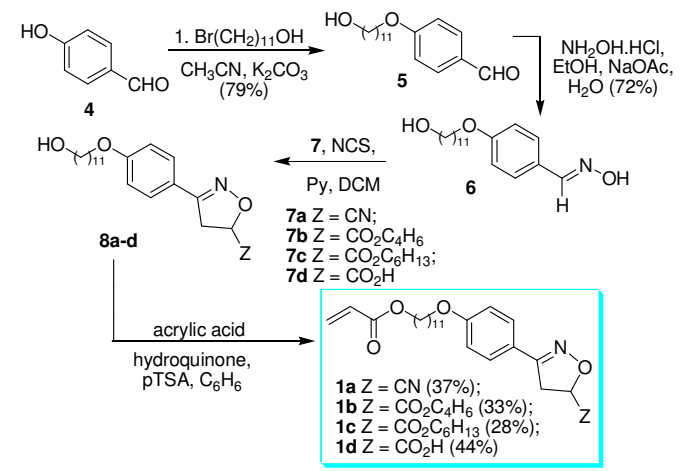

Scheme 2. Synthesis of the monomers 1a-d.

The next step was to synthesize $8 \mathbf{a}-\mathbf{d}$ using the cycloaddition [3+2] 1,3-dipolar between aryl nitrile oxide derived from 6 and dipolarophiles 7a-d. The oxime 6 was reacted with the dipolarophiles $7 \mathrm{a}-\mathrm{d}$ in the presence of $\mathrm{N}$-chlorosuccinimide, pyridine in dichloromethane. 8a-d were obtained in $61 \%-89 \%$ yields. The monomers 1a-d were prepared through esterification between the isoxazoline $\mathbf{8 a}$-d and acrylic acid with low yields after $28 \%-44 \%$ yield.

The chiral monomer 2 was prepared by coupling between (-)-menthol and acrylic acid in $65 \%$ yield. The copolymers 3a-d were prepared in molar proportion between the monomers 1a-d and the monomer 2 in 70:30 and the copolymer $3 \mathbf{e}$ with the monomer $\mathbf{1 c}$ and the monomer $\mathbf{2}$ in a molar proportion of 90:10.

The copolymers were analyzed with GPC, DSC and the molar proportion was confirmed with NMR ${ }^{1} \mathrm{H}$ analysis (Table 1 ).

Table 1: GPC and DSC data of copolymers 3a-e. a $^{-}$

\begin{tabular}{|c|c|c|c|c|}
\hline Copolymers & $\mathbf{T g}\left({ }^{\circ} \mathbf{C}\right)$ & $\mathbf{M n}$ & $\mathbf{M w}$ & PD \\
\hline 3a & 0 & 6,429 & 8,148 & 1.27 \\
\hline 3b & 0 & 10,153 & 18,372 & 1.81 \\
\hline 3c & 16.2 & 12,800 & 18,508 & 1.45 \\
\hline 3d & 27.5 & 13,239 & 24,201 & 1.83 \\
\hline 3e & -10.0 & 8,836 & 10,500 & 1.18 \\
\hline
\end{tabular}

$\stackrel{a}{9}$ : glass transition temperature; Mn: number-average molecular weight; Mw: weight-average molecular weight; PD: polydispersity.

The DSC analysis showed that the copolymers 3a-e are amorphous with $\mathrm{Tg}$ between $-10^{\circ} \mathrm{C}$ and $27.5^{\circ} \mathrm{C}$. The $\mathrm{Mn}$ copolymers $3 \mathrm{a}-\mathrm{e}$ are in the range of $6,429-13,239$ daltons. No mesomorphic behavior was observed for all samples.

\section{CONCLUSION}

Comb-shape Polyacrylates copolymers with side chains 3a-e were synthesized and characterized. The copolymers are amorphous with low glass temperature transition.

\section{ACKNOWLEDGEMENTS}

Thanks to UFRGS, INCT-Catálises and CAPES.

\section{REFERENCES}

Kumar, G.; Nisha, N.; Mageswari, S.; Subramanian, K. J. Polym. Res. 2011, 18, 241.

${ }^{2}$ Mohamed, M. H.; Wilson, L. D.; Headley, J. V. Carbohydr. Res. 2011, 346, 219.

${ }^{3}$ Passo, J. A.; Vilela, G. D.; Schneider, P. H.; Ritter, O. M. S.; Merlo, A. A. Liq. Cryst. 2008, 35, 833. 